\title{
Response to "Considering the Potential Benefits of Over-the-Counter Naloxone" by Evoy et al [Letter]
}

\section{Brian Fuehrlein}

VA Connecticut Healthcare System, West Haven, CT, USA
Correspondence: Brian Fuehrlein VA Connecticut Healthcare System, West Haven, CT 06516, USA

Email brian.fuehrlein@yale.edu

\section{Dear editor}

Evoy et $\mathrm{al}^{1}$ are to be commended for their cogent and thorough review of the potential benefits of over-the-counter (OTC) naloxone. Expanding access to this life-saving medication has the potential to reduce opioid overdose mortality and be a net benefit to the community. It is concerning, however, that the introduction of OTC naloxone may also have the unintended effect of impeding the identification and treatment of the root cause of opioid overdose: opioid use disorder (OUD).

OUD is a chronic, relapsing brain disease ${ }^{2,3}$ that affects approximately 1.6 million people in the United States. ${ }^{4}$ Like other chronic diseases with a strong psychological and behavioral component, management of OUD requires a multifactorial approach centered around pharmacological maintenance treatment coupled with psychosocial interventions and support. Naloxone, although essential for overdose reversal, is not a maintenance treatment for OUD. Instead, it treats a symptom of the illness (overdose). Although treating this particular symptom is essential, it is not sufficient unless it is part of a comprehensive response to the underlying disorder. To use another chronic disease as an example, diabetic ketoacidosis (DKA) is a potentially deadly symptom of poorly controlled diabetes. If an OTC treatment for DKA existed, it would help save lives in the short term. However, unless it was a part of a broader treatment response that included treatment of the underlying diabetes, it would not live up to its full lifesaving potential.

A variety of effective pharmacological treatment options are currently available for the management of OUD. ${ }^{3}$ Methadone, buprenorphine, and extended-release naltrexone are evidence-based medication management options that, in conjunction with behavioral treatment, can both improve survival and reduce the medical, economic, and societal toll of OUD. ${ }^{5}$ In a world where naloxone is readily available without the involvement of healthcare professionals, fewer people with OUD may find their way to maintenance therapy. Were this to occur, the short-term net positive of fewer fatal overdoses would be outweighed by the long-term negative effect of fewer people receiving treatment and achieving recovery from OUD.

To be clear, the idea of OTC naloxone is critical. However, to maximize the utility of this standard of care life-saving medication, it must be coupled with a comprehensive, evidence-based response to the underlying disorder that includes maintenance medication as well as behavioral interventions and psychosocial support. 
There should be a deliberate approach to any OTC transition that includes initial and ongoing education on the disease process and referral to community treatment options.

\section{Acknowledgments}

Editorial support was provided by The Curry Rockefeller Group, LLC (Tarrytown, NY), and was funded by Emergent BioSolutions Inc. (Gaithersburg, MD).

\section{Disclosure}

The author reports no conflicts of interest in this communication.

\section{References}

1. Evoy KE, Hill LG, Davis CS. Considering the potential benefits of over-the-counter naloxone. Integr Pharm Res Pract. 2021;10:13-21. doi:10.2147/IPRP.S244709
2. Schiller EY, Goyal A, Mechanic OJ. Opioid Overdose. Treasure Island, FL: StatPearls Publishing; 2020.

3. American Society of Addiction Medicine. The ASAM National Practice Guideline for the Treatment of Opioid Use Disorder: 2020 Focused Update. Rockville, MD: American Society of Addiction Medicine; 2020.

4. Substance Abuse and Mental Health Services Administration (SAMHSA). Key Substance Use and Mental Health Indicators in the United States: Results from the 2019 National Survey on Drug Use and Health (Publication \# PEP20-07-01-001). Rockville, MD: Substance Abuse and Mental Health Services Administration; 2020.

5. Volkow ND, Jones EB, Einstein EB, Wargo EM. Prevention and treatment of opioid misuse and addiction: a review. JAMA Psychiatry. 2019;76(2):208-216. doi:10.1001/jamapsychiatry.2018.3126

Dove Medical Press encourages responsible, free and frank academic debate. The content of the Integrated Pharmacy Research and Practice 'letters to the editor' section does not necessarily represent the views of Dove Medical Press, its officers, agents, employees, related entities or the Integrated Pharmacy Research and Practice editors. While all reasonable steps have been taken to confirm the content of each letter, Dove Medical Press accepts no liability in respect of the content of any letter, nor is it responsible for the content and accuracy of any letter to the editor.

\section{Publish your work in this journal}

Integrated Pharmacy Research and Practice is an international, peerreviewed, open access, online journal, publishing original research, reports, reviews and commentaries on all areas of academic and professional pharmacy practice. This journal aims to represent the academic output of pharmacists and pharmacy practice with particular focus on integrated care. All papers are carefully peer reviewed to ensure the highest standards as well as ensuring that we are informing and stimulating pharmaceutical professionals. The manuscript management system is completely online and includes a very quick and fair peer-review system, which is all easy to use. Visit http://www.dovepress.com/testimonials.php to read real quotes from published authors. 